\section{Transvaginal subfascial synthetic mesh sling in female stress urinary incontinence: A Novel technique}

\author{
Abdul Rouf Khawaja, ${ }^{1}$ Farzana Bashir, ${ }^{2}$ \\ Arif Bhat, ${ }^{1}$ Yaser Dar, ${ }^{1}$ Sajad Malik, ${ }^{1}$ \\ Saleem Wani ${ }^{1}$ \\ ${ }^{1}$ Department of Urology Sheri-Kashmir \\ Institute of Medical sciences (SKIMS) \\ Soura Srinagar Kashmir; ${ }^{2}$ Government \\ Medical college Department of OBG \\ (L. D. Hospital) Srinagar Kashmir, India
}

\begin{abstract}
The object of this paper is to assess the treatment outcome and overall efficacy of a novel technique of transvaginal subfascial synthetic mesh for female stress urinary incontinence. The study included 53 patients of female stress urinary incontinence managed at our institution between
\end{abstract} March 2005 and December 2015. Preoperative evaluation included a detailed history, base-line investigations and cystoscopic examination including stress test, uroflometry with residual urine was done in all cases. Lower urinary tract imaging and urodynamic evaluation was done in selected cases . patients with concomitant pelvic organ prolapse and severe BMI were excluded from the study. All patients underwent a transvaginal subfascial sling procedure under regional anesthesia. Urethral catheter was removed the day after procedure. Post procedure results were assessed in terms of improvement in stress urinary incontinence, procedure related complications, and overall satisfaction of the patient. Mean age of the patients was 43.5 years (25-63 years). All patients were multiparous. Complete resolution of symptoms in 49 patients $(92.4 \%)$ while in 4 patients (7.5\%) had some degree of SUI. Urinary retention in $3(5.6 \%)$, increased frequency in $5(9.4 \%)$ patients and urge incontinence in $2(3.7 \%)$ One $(1.8 \%)$ had mesh erosion at 3 months after the procedure. None of the patient had any sexual dysfunction on follow up. Overall success rate of the procedure was around 93\%.However patients with preoperatively urge incontinence needs anticholinergics in post operative period for 1-2 months. Operative time was $30-45$ minutes. Three patients $(5.6 \%)$ who experience transient postoperative retention had no symptoms of SUI on follow up. Transvaginal subfascial sling is a modification of the original mid urethral sling proce- dure with an advantage of being less invasive, simpler to learn and achieve similar results compared to other sling procedures.

\section{Introduction}

SUI is a disease that is closely related to the quality of life. The mid urethral sling operations as retropubic Tension free Vaginal Tape (TVT) was reported by Ulmsten and Petros ${ }^{1}$ and the Transobturator tape (TOT) by Delorme. ${ }^{2}$ These midurethral sling operations became the most popular procedures and showed exponential growth in cases. This operation is still evolving in materials and technique. ${ }^{3}$ Theoretically, the midurethral sling involves a suburethral support mechanism. ${ }^{4,5}$ These procedure produces dynamic urethral compression during the voiding phase. ${ }^{3}$ Failures are as low as $5.7 \%$ for the transobturator and $7.8 \%$ for the retropubic procedures. Perioperative complications are only $0.8 \%$ for transobturator and $5.5 \%$ for retropubic procedures. ${ }^{6}$ In our few initial cases TOT needle (Figure 1) had inadvertently gone superfascial to ischiopubic rami without piercing the obturator membrane and, on follow up patient had groin pain for which ultrasound of perineum was done which reveals mesh has not pierced the obturator membrane, but patient had complete resolution of stress urinary incontinence. Using the technique and surgical principles of transobturator route, we describe a new, simple minimally invasive, easy to learn, and cost effective method, which we term Transvaginal Subfascial sling (TVSS), that consists of placement of sling at mid urethral level and brought superfascial to ischiopubic rami throught the small incision at groin on both sides. With this novel technique we start this procedure for stress urinary urinary incontinence and all details were discussed with the patient and consent was sought.

\section{Materials and Methods}

The study included 53 patients of female stress urinary incontinence managed at our institution between March 2005 and December 2015. Preoperative evaluation included a detailed history, base-line investigations and cystoscopic examination including stress test, uroflometry with residual urine was done in all cases. Lower urinary tract imaging and urodynamic evaluation was done in selected cases. Urodynamics was done with history of obstructive LUTS associated with stress incontinence. Patients with severe BMI
Correspondence: Abdul Rouf Khawaja, SheriKashmir Institute of Medical sciences, Department of Urology, SKIMS main road Soura, 190011 srinagar Kashmir, India. Tel.: 9419087992.

E-mail: roufkhawaja@rediffmail.com

Key words: Voiding dysfunction; stress incontinence; denovo urge incontinence; transvaginal subfascial sling.

Acknowledgments: Department of Urology (skims), Department of OBG(skims), Department of OBG (L.D Hospital)

Contributions: ARK conception and design, drafting the manuscript and data acquisition; FB data analysis and interpretation, $\mathrm{AB}$ critical revision of the manuscript for scientific and factual content; YD data analysis and data acquisition; SM drafting the manuscript; SW statistical analysis and supervision.

Conflict of interests: The authors declare no conflicts of interest.

Ethics approval and consent to participate: The study was approved by the Institution Ethics committee.

Consent for publication: The patient gave their written consent to use their personal data for the publication of this case report and any accompanying images.

Availability of data and materials: All data underlying the findings are fully available.

Received for publication: 28 December 2019. Accepted for publication: 6 January 2021.

This work is licensed under a Creative Commons Attribution NonCommercial 4.0 License (CC BY-NC 4.0).

(C) Copyright: the Author(s), 2020

Licensee PAGEPress, Italy

Urogynaecologia 2020; 32:218

doi:10.4081/uij.2020.218

were excluded from the study and were advised for weight reduction programme before planned for TVSS. Inclusion criteria were: female, suffering frorm stress urinary incontinence. Exclusion criteria included stress urinary incontinence associated with pelvic organ prolapsed and severe OAB. All patients underwent a transvaginal subfascial sling procedure under regional anesthesia. Per urethral catheter was removed on the first day after the procedure. Post procedure results were assessed in terms of improvement in stress incontinence, procedure related complications, and overall satisfaction of the patient. All patients were assessed at 3 months, 6 months and 1 year. However, suc- 
cess rate was assessed at first follow up at 3 months. On each follow up the woman underwent the cough stress test, and were asked about improvement in symptomatology of stress incontinence, and if any sexual dysfunction was noted. All patients underwent uroflometry and ultrasound for residual urine at 3 months follow up. Any other untoward effect related to lower urinary tract during follow up was also noted.

\section{Surgical Technique}

The TVSS procedure (Figure 2) was performed under spinal anaesthesia. The patient was placed in lithotomy position. The lower abdomen and genital were prepared with diluted savlon and betadine and was drapped in a sterile fashion. An 16-18fr Foley catheter was indwelled per urethra, and mid urethra was identified. The safe entry point for the needle is the intersection point of perpendicular line from the insertion of Adductor longus and horizontal line from the tip of clitoris. The points at which these lines intersect each other corresponds to entry of needle for TVSS. An allis clamp was used to grasp the anterior vaginal wall and $2 \mathrm{~cm}$ vertical incision was given just $1 \mathrm{~cm}$ proximal to the external urethral meatus. A suburethral tunnel was created in the anterior vaginal wall after hydrodissection. Ischiopubic ramus is felt with index finger and tunneler device (standard tunneler needle for TOT) is introduced from outside with finger acting as a guide so that the tip of needle passes superfascial to corresponding ischiopubic ramus. Tip of the TOT needle is brought out from the incision in the vaginal wall and thread of one end of TOT tape is fed through the eye of the TOT needle and needle is withdrawn through the same path superfacial to ischiopubic rami to original incision in the groin. Similar procedure is repeated on other side also. A $2 \mathrm{x}$ $39.8 \mathrm{~cm}$ non absorbable undyed monofilament polypropylene mesh sling was used in our study. The sling was adjusted with a scissor so that it would lie under the midurethra with minimal tension. As the procedure were performed under spinal anaesthesia, the patients were instructed to strain by coughing after filling the bladder about the capacity $300 \mathrm{~mL}$ saline to determine whether the tightness of the sling needed adjustment. Both ends of the sling are cut beneath the skin incision in the groin. Anterior vaginal wall incision was closed in two layers using vicryl 4-0 suture. Sterile dressings is applied on skin incisioins in groin. Betadine soaked gauze was kept in vaginal introitus.

\section{Post operative care}

The Foley catheter was removed after 24 hours. Betadine soaked gauze was removed in It POD. Patients were instructed to void spontaneously after catheter removal and used betadine pessaries for one week. All patients were discharged on $2^{\text {nd }}$ POD with post void residual urine estimation. Volume of less than $50 \mathrm{ml}$ were discharged and volume of more than $100 \mathrm{~mL}$ were taught for self clean intermittent catheterization before being discharged. Patients were advised to start normal daily routine activities after discharge from hospital, to maintain local hygiene, to avoid straining and lifting heavy weights for 3-4 weeks and to avoid sexual activity for $4-6$ weeks. Patients with earlier detrusor overactive were advised to take anticholinergics if bothersome urge incontinence occurs.

\section{Results}

Mean age of the patients was 43.5 years (25-63 years, Table 1). All patients were multiparous. Operative time from starting the incision to closure of incision is $24-45$ minutes only and the mean operative time of 30 minutes. No intraoperative complication occurred (Table2). Complete resolution of symptoms in 49 patients $(92.4 \%)$ while in 4 patients $(7.5 \%)$ had some degree of stress urinary incontinence. Post operative complications included urinary retention in $3(5.6 \%)$,increased frequency of urination in $5(9.4 \%)$ patients and urge incontinence in $2(3.7 \%)$ patients. One $(1.8 \%)$ patient had mesh erosion at 3 months after the procedure Reason for mesh erosion was infection. None of the patient had any sexual dysfunction on follow up. We followed
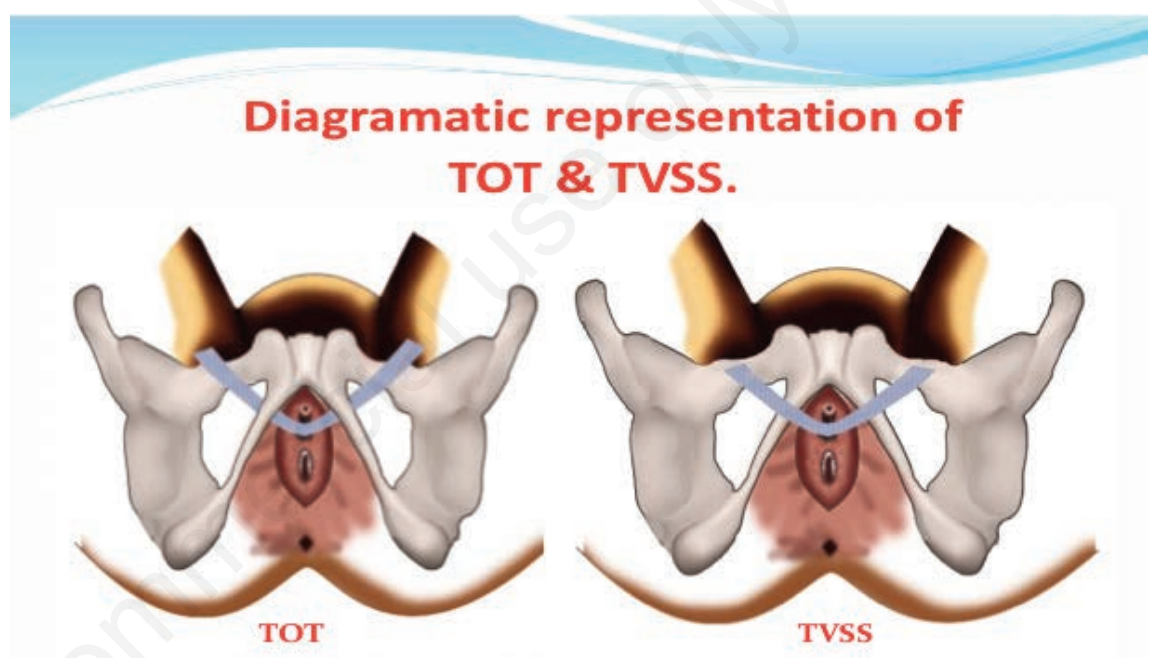

Figure 1. Comparison between Trans obturator tape and trans vaginal subfascial sling.
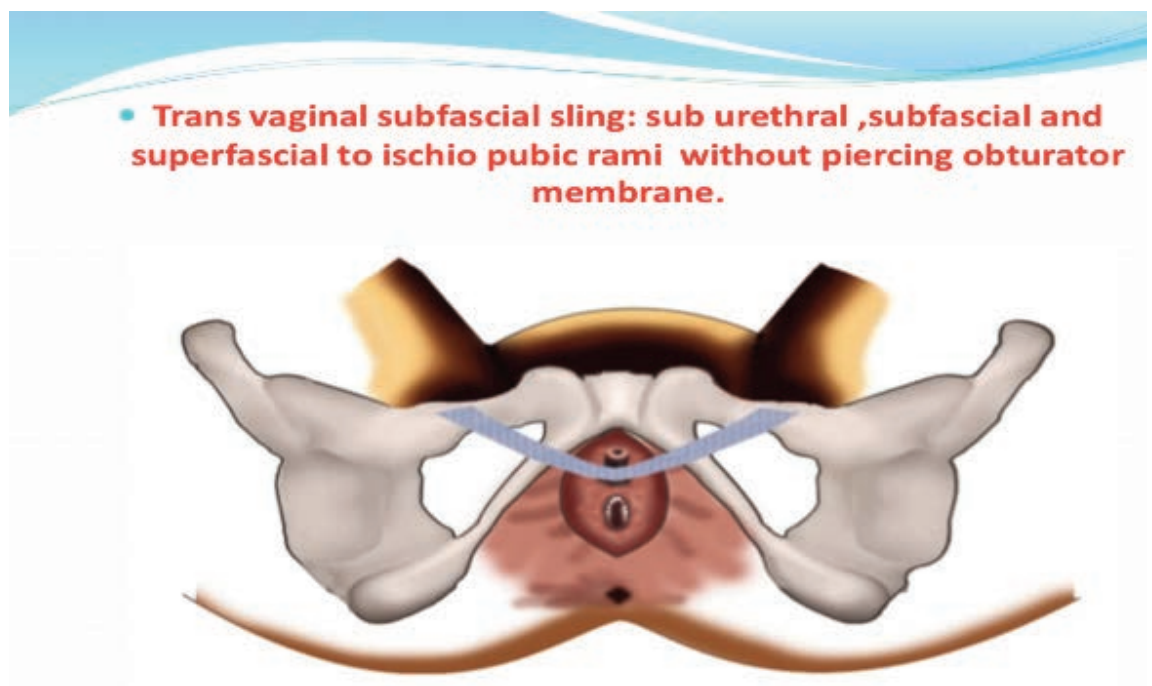

Figure 2. Trans vaginal subfascial sling. 
Female Sexual Function Index (FSFI). Overall success rate of the procedure was around $93 \%$. With a follow up of around 10 years almost $93 \%$ of the patients were satisfied with the procedure, only $4 \%$ of patients were unsatisfied with the procedure. We follow two patient satisfaction questionnaires as surgery satisfaction questionnaire and consultation satisfaction questionnaire. Aim of this novel technique was effectiveness of transvaginal subfacial sling in curing the stress incontinence in female population. Resolution of stress incontinence and patient satisfaction was accepted as functional success. However, more comparative study for TVSS with standard procedure for stress incontinence in females as a procedure of choice are needed.

\section{Discussion}

Urethral slings are currently the procedure of choice for the surgical correction of female stress urinary incontinence. A variety of materials and techniques have been pursued for sling placement. Unlike the pubovaginal slings, the midurethral slings should be placed loosely at the midportion

Table 1. Clinical profile of the patients $(n=53$ patients).

\begin{tabular}{ll}
\hline Age in years & \\
$25-35$ years & 18 \\
$35-45$ years & 30 \\
$>45$ years & 05 \\
Symptomatology & \\
Predominant stress incontinence & 38 \\
Stress a/w urge incontinence & 15 \\
\hline
\end{tabular}

Table 2. Results of study.

\begin{tabular}{lc}
\hline Satisfaction & \\
Satisfactory & 48 \\
Unsatisfactory & 05 \\
Resolution of sui & \\
Complete resolution & 49 \\
Partial resolution & 04 \\
\hline Complications & \\
a)Intraoperative & nil \\
b)postoperative & \\
Poor flow & nil \\
SIEV & 2 \\
De novo urgeincontinence & nil \\
Mesh perforation & nil \\
Mesh exposure & 01 \\
Sexual Dysfunction & nil \\
Continuous intermittent catheterization) & nil \\
\hline
\end{tabular}

of the urethra. In woman who are continent, maximum urethral closure pressures occur at the mid urethra and that this phenomenon is most likely caused by the confluence of anatomic structures in that area. The three separate components that support the proximal and mid urethra are pubourethral ligaments, the suburethral vaginal hammock, and the pubococcygeus muscle. Pubovaginal slings are placed under mild tension at the bladder neck to reestablish the suburethral hammock, and midurethral slings are placed loosely at the midurethra to prevent movement of the posterior urethral wall. Currently, a soft, loosely woven, polypropylene monofilament mesh with a pore size exceeding 75 micrometer, permitting passage of macrophages and excellent host tissue ingrowth. Based on this concept of mid urethral slings we introduced a novel technique (Figure 2) called as Trans Vaginal Subfascial Sling (TVSS) for the surgical correction of female stress urinary incontinence. In our technique as the sling is loosely placed at the mid urethra and sling passes superfascial to corresponding ischiopubic rami. As the sling is placed in suburethral region the synthetic material promote organized fibrosis and reinforce the sphinteric mechanism through improved urethral support. The female urethra lies under the pubic symphysis and the pubourethral ligaments suspend the anterior urethral wall to pubic arch. In case of Valsalva or stress maneuvers the posterior wall of the urethra slide away from anterior urethral wall which in turn open the bladder neck and proximal urethra with resultant incontinence. Based on this mechanism we believe that suburethral support in form of mesh with organized fibrosis is enough to prevent the movement of posterior urethral wall during stress or Valsalva maneuvers to prevent stress incontinence. In our study as the mesh is placed superfascial to ischiopubic rami through subcutaneous tissue and exit through the same point as described in transobturator out in technique. Over time the mesh placed becomes fixed in subfascial space and suburethral region and in these locations is enough for support to prevent movement of posterior urethra during stress. We believe this technique is quite simple without traversing the transobturator membrane and avoiding any injury to neurovascular bundle/any anomalous vessels in obturator canal. In our study majority of the patients were in age group $35-45$ years (Table1) and predominant symptom was stress incontinence with bothersome symptoms associated poor esteem. Majority of the patients were satisfied at 3 months interval and were almost dry on stress maneuvers. On follow up one patients had urethral erosion at 3 months interval which were removed locally. None of our patients required intraoperatively cystoscope for any perforation of the mesh. Based on our results over a period of 10 years we believe this technique is durable simple to learn without any injury to obturator vasculature. To our knowledge no such technique is described in literature. Our study has certain limitations because of small sample size with a follow up for 10 years and needs comparative study with standard Transobturator technique and it will be premature to consider as an alternative technique for female stress incontinence.

\section{Conclusions}

Transvaginal subfascial sling is a modification of the original mid urethral sling procedure with an advantage of being less invasive, simpler to learn and achieve similar results compared to other standard sling procedures.

\section{References}

1. Ulmsten U, Petros P. Intravaginal slingplasty (IVS): An Ambulatory surgical procedure for treatment of female urinary incontinence. Scand J Urol Nephrol 1995;29:75-82.

2. Delorme E. Transobturator urethral suspension: Miniinvasive procedure in the treatment of stress urinary incontinence in women. Prog Urol 2001;11:1306-13.

3. Bullock TL, Ghoniem G, Klutke CG, Staskin DR. Advances in female stress urinary incontinence: mid-urethral slings. BJU Int 2006;98:32-40.

4. DeLancey JO. Structural support of the urethra as it relates to stress urinary incontinence: the hammock hypothesis. Am J Obstet Gynecol 1994;170:171320.

5. Petros PE, Ulmsten UI. An integral theory of female urinary incontinence. Experimental and clinical considerations. Acta Obstet Gynecol Scand Suppl 1990;153:7-31.

6. Sung VW, Schleinitz MD, Rardin CR, et al. Comparison of retropubic vs transobturator approach to midurethral slings: A systematic review and metaanalysis. Am J Obstet Gynecol 2007;197:3-11. 